\title{
Legal Exploration on the Currency Sovereignty of China in the Financial Globalization Environment
}

\author{
Zhang Ruixiong \\ Beijing Foreign Studies University, Law School, Master of international law,10089 \\ hunter2011@foxmail.com
}

Keywords: Financial globalization; Currency sovereignty; Financial crisis; Exchange rate changes

\begin{abstract}
The national economic sovereignty is the indivisible part of national sovereignty, and the currency sovereignty comes from economic sovereignty. In international law, sovereignty is the fundamental characters of a nation and means the top power of a nation to separately and independently deal with domestic and foreign affairs. Today when finance has been globalized, the national currency sovereignty is still facing the impact from financial renovation and development of scientific technologies, while the implementation of the currency sovereignty of development nations are especially facing the impact from financially powerful countries. The researches on national currency sovereignty under the background of the hot issue of financial crisis and Renminbi currency are of more realistic meaning. This article is just studying this issue.
\end{abstract}

\section{Concept and legal confirmation of national currency sovereignty}

The concept and contents of national currency sovereignty. National currency sovereignty is the fundamental contents of economic sovereignty principle as well as one of the core meanings of the autonomous right of a nation on its national issues. National currency sovereignty is the top power of nation to issue and manage the currency in its own territory as well as the right to independently implement its foreign currency policies and equally taking part in the treatment of international currency and financial affairs during international economic interaction.

Currency sovereignty includes various kinds of power and policy tools, such as that for domestic affairs, a nation is entitled to or could freely confirm currency units, issue legal currencies like cash and coins, punish behaviors of forging currencies, forbidding the circulation of other currencies within its territory, regulate the currency supplying and bank system, and confirm or change the value of its currency; while for foreign affairs, currency sovereignty means that every nation may realize limitation and regulation on international payment and capital transferring, choose exchange rate arrangement and exchange rate system, set up the exchanging ratio of currency, and abide by the international obligations and currency disciplines provided in treaties so as to maintain the order of international currency.

The legal confirmation of currency sovereignty. The limitation on national currency sovereignty is actually the manifestation and results of a nation implementing its sovereignty. In order to realize cooperation and win-win within the era of economic globalization, all nations need to pursue some mutual compromise and assignment of currency sovereignty within some scope so as to exchange for and obtain the conditions, space and interest needed by the survival and development in the era of globalization, among which one of the important interest is that one nation could render other members of the international society to be limited in the same way through limiting and assign some of the currency sovereignty of themselves so as to form the international economic orders that are sure to be needed in the conditions of globalization. Another important interest is to conditionally assign the currency sovereignty into international organizations and enjoy related interest while fulfilling related obligations.

\section{International regulations on currency sovereignty}

Regulations on currency sovereignty in IMF agreement. The regulations on currency sovereignty in IMF (International Monetary Fund Organization) agreement are mainly about the 
rules on controlling of foreign currencies. The fundamental reason for the implementation of controlling of foreign currencies is to guarantee the development of domestic economy and finance, stabilize the domestic financial order, avoid currency credibility crisis, improve and balance income and expenditure, prevent or relieve international crisis in income and expenditure, ensure the normal and healthy development of foreign economy. Controlling of foreign currency is the major constituent part of the national currency and financial laws and policies and is of important meaning to national economy. Laws of Foreign Currency Control is the sum of the laws, regulations, and ordinances enacted by a nation for implementing foreign currency controlling, and it is of important effect to the economic life of a nation especially those nations that are not developed and weaker in economic power because controlling of foreign currency is the important constituent part of the national financial and economic policies, especially foreign currencies.

Rules and norms on national currencies in WTO regulations. Usually the regulation of exchange rate is beyond the legal system of the World Trade Organization, but there are also related regulations within the framework of WTO, which is mainly manifested by Article 15 in "General Agreement On Tariffs And Trade (GATT) 94" providing that issues about currency reserve, international income and expenditure, or foreign exchange arrangement must be negotiated with IMF and accepts the decision of IMF as well as Article 11 providing that implementation of limitation by member nations of WTO on the international transferring and payment of current transactions related to its specific promises is prohibited and no limitations inconsistent to the specific promises related to this type of transaction are allowed to be set for any capital transaction.

But these two articles had all explicitly showed that the limitation in the conventions must not interfere with the effect of the rights and obligations of the member nations endowed by "Fund Convention" including the remittance and exchange behaviors allowed by "Fund Convention". On the other hands, although there is no regulation on most-favored-nation treatment in the "Fund Convention", it still requires the member nations to be sure to cooperate with the fund organization and other member nations so as to guarantee the foreign exchange order and stable exchange rate system. If the member nations have implemented discriminated exchange rate measures or applied differential exchange rates to the import of different nations in a discriminated way, it certainly constitute the violation of the legal system and most-favored-nation principle of WTO, under which condition the exchange rate measure violating the most-favored-nation principle of WTO also infringes the principles in "Fund Convention".

\section{Effect of the financial globalization environment on the currency sovereignty of China}

Impact of financial renovation on the currency sovereignty of China. The impact of financial renovation on the currency sovereignty of China is first manifested as the weakening of the nation rights of issuing currency. The continuous deepening of financial innovation has brought about a lot of new financial tools including new credit tools and saving types that are of extreme moneyness, such as Money Market Mutual Fund (MMMFs), commercial bank bills, liquidate capital acceptance documents, supper transferrable check accounts, and automatic account transferring service, etc. These creative financial tools have unprecedentedly increased the substitutability among financial assets, thus rendering it is more and more difficult to clearly distinguish the currency as currency from those as capital.

The effect of financial renovation has promoted the continuous extension of the statistical specifications of the currencies in all nations, among which there are many nations having expanded the original M1 to M4 on the basis of M0 and the currency statistical specification of the UK even had been extended to be M7, while some other nations like Japan had to adopt flexible rules of generalization, that is, the new M2+CD+ financial tools when defining the currency flow. These new types of circulation measures without legal features had actually borne the function of currency circulation within the market and already constituted currency substitutes, so all nations have to include these financial tools functioning as currency circulation when formulating currency policies.

However, it is not hard to find that the main bodies issuing these currency financial renovation new tools are not the central banks regulated by the currency laws in all nations or the institutions 
authorized by the nation for issuing currencies, and their issuers are mostly common commercial banks or even non-commercial financial institutions. According to the legal regulations of legal tender and related currency issuing rights, financial renovation has led to infringement on national currency issuing rights to some degree on this point.

Impact of currency renovation on national currency sovereignty. In recent years with the progress of scientific technology and improvement of the living levels of human being, value cards have been applied in a more and more comprehensive way. Usually value cards are divided into bank value cards and non-bank value cards. The using mode of value cards is that it is used after payment is first made, through which method the enterprises issuing cards had obtained a great amount of capital. Because these assets are collected by non-bank institutions, so this kind of asset is regarded as "department currency". The issuers of department currency had intentionally or unintentionally confused and even stolen national credibility through issuance of value cards, and the space for the usage of legal currency had been squeezed, it is impossible to master the target value and actual value of the amount of the circulated currency, it is hard to predict inflation (deflation), and the currency issuance authority as well as the transmission and realization of currency policies of central banks will be all affected.

Secondly, department currency had blurred the currency levels of traditional currencies and interfered the selection of the regulating and controlling modes of different levels of currency supplying amount by the central bank. The formulation and implementation of currency policies are the important tools for the current central banks of all nations to implement macro regulating and controlling functions. The purpose of the implementation of currency policies is to utilize multiple kinds of currency policy tools to realize the balance of total supply and total demand of currency, that is, the currency policy purpose of currency value stabilization, so as to create a good macro financial environment for the development of economy. The realization of currency policy goals depends on appropriated intermediate purposes and effective policy tools.

Because department currency has partly substituted the cash and deposit in circulation, so it has not only changed the structure of currency supply but also rendered the mutual transmission of traditional currencies among different currency levels, thus leading to blur boundary among various kinds of currency levels and then challenging that the central bank when determining the models for regulating and controlling of the amount of currency supply of the monitored targets according to the degree of the effect on economy by different levels of currency supplying amount.

Impact of scientific progress on national currency sovereignty. With the notion of new technology becoming mature in the financial area, the profit increasing point of banks has turned to the new areas of the transaction of derivative products, while the market of financial derivative tools transaction has been filled with high risks due to the high leverage effect and the duplicity of avoidance of risks and speculation for profit of financial derivatives. However, deficiency exists in the current legal system for information disclosure and transaction transparency degree regulation of banks within the transaction of financial derivative products. The current legal regulation systems or measures related to financial derivative transactions, especially the information disclosure and specialists obligation system involving protection of investors are not only insufficient for determining the safety and of integrity of individual financial institutions but also unable to prevent the occurrence of systematic risk in financial system.

The development of financing securitization has also continuously deteriorated the environment for the operation of banking industry, thus hindering the operation of the functioning mechanism of the national currency policies and affecting the implementation and effect of currency policies. The gradual mixing of the operation of financial business has rendered it more and more difficult to discriminate banks from non-bank institutions. The development of off-balance sheet of banking business had reduced the requirement on aspects including reserve funds, guaranty money for deposits, and capital. It is also hard for bank to be independently secure during the era of turmoil in security market due to the co-movement of the systematic risk of banks and risks in security market in modern risk society. 


\section{Status of the changes of RMB exchange rates and the prediction models}

Status of the changes of RMB exchange rates. This article has taken the RMB exchange rates during the period from 2005 to 2013 as the data basis to analyze the effect of the changing of RMB exchange rates during these nine years on the status of the development of Chinese society and economy. The results thus obtained are shown in Table 1 and Figure 1.

Table 1: Data statistics of the RMB exchange rate, GDP, total amount of import and export, and consumer price index data during the period from 2005 to 2013

\begin{tabular}{|c|c|c|c|c|c|}
\hline Year & $\begin{array}{c}\text { RMB } \\
\text { exchange rate }\end{array}$ & $\begin{array}{c}\text { Exchange Rate } \\
\text { Changing }\end{array}$ & $\begin{array}{c}\text { GDP (RMB 100 } \\
\text { million Yuan) }\end{array}$ & $\begin{array}{l}\text { Total amount of import } \\
\text { and export (RMB 100 } \\
\text { million Yuan) }\end{array}$ & $\begin{array}{l}\text { Consumer } \\
\text { price index }\end{array}$ \\
\hline 2005 & 8.1917 & & 185895.8 & 54273.70 & 464.0 \\
\hline 2006 & 7.9718 & $-2.76 \%$ & 217656.6 & 63376.86 & 471.0 \\
\hline 2007 & 7.604 & $-4.84 \%$ & 268019.4 & 73300.10 & 493.6 \\
\hline 2008 & 6.9451 & $-9.49 \%$ & 316751.7 & 79526.53 & 522.7 \\
\hline 2009 & 6.831 & $-1.67 \%$ & 345629.2 & 68618.37 & 519.0 \\
\hline 2010 & 6.7965 & $-0.51 \%$ & 408903 & 94699.30 & 536.1 \\
\hline 2011 & 6.4588 & $-5.23 \%$ & 484123.5 & 113161.40 & 565.0 \\
\hline 2012 & 6.3125 & $-2.32 \%$ & 534123 & 114800.96 & 579.7 \\
\hline 2013 & 6.1932 & $-1.93 \%$ & 588018.8 & 121037.46 & 594.8 \\
\hline
\end{tabular}

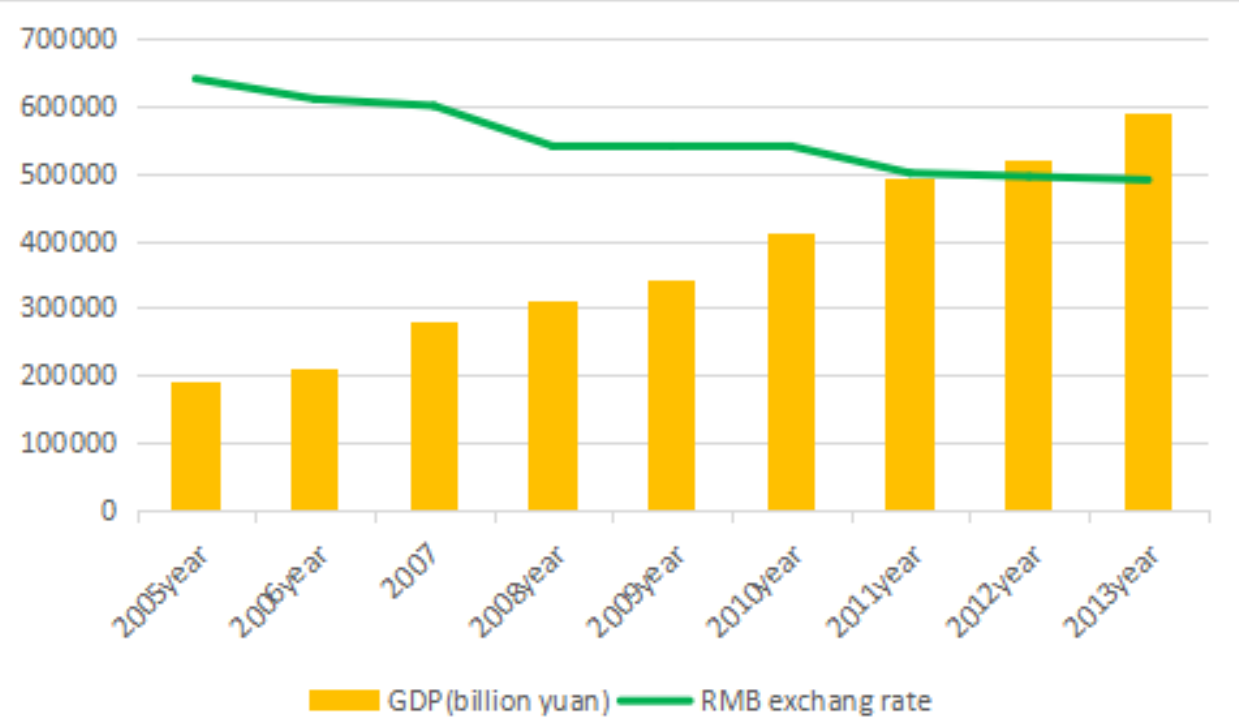

Fig. 1: Picture of the changing trends of RMB exchange rates and GDP in every year during the period from 2005 to 2015

The relationship equation for related variables made by SPPS software is as below:

$$
\begin{gathered}
y=5.287+\frac{564773.650}{x} \\
R^{2}=0.973
\end{gathered}
$$

Among which $\mathrm{y}$ is the RMB exchange rates while $\mathrm{x}$ is the Gross Domestic Product (GDP)

The correlation equation degree of both is $R^{2}=0.973$, indicating that there is a strong cause and effect relationship between the two. Figure 2 is the fitting picture showing the relationship between the two, thus directly manifesting the strong correlation between the two.

The prediction model of the changing of RMB exchange rates. This article will take the method of weighted average combining the three kinds of prediction methods including time series method, regression analysis method, and grey prediction methods to realize the prediction on the development trend of RMB exchange rates in the "thirteenth five years" and the "fourteenth five years". Table 2 and Table 3 are the prediction models and the prediction data. Figure 2 is the 
prediction trend picture. It could be seen that the average annual reduction rate during the period of the thirteenth five years was $0.31 \%$ while that in the period of the fourteenth five years was $0.09 \%$. It could be concluded that with the reduction of RMB exchange rates the value of RMB has been continuously increased with the comprehensive national power also kept being enhanced.

Table 2: RMB exchange rate prediction methods and models

\begin{tabular}{|c|c|c|c|}
\hline & Prediction model & Variable interpretation & $\begin{array}{l}\text { Examination } \\
\text { indexes }\end{array}$ \\
\hline $\begin{array}{l}\text { Logarithmic } \\
\text { growth } \\
\text { curve model }\end{array}$ & $y=161.173-20.380 \ln x$ & $\mathrm{x}$ : Time sequence & $\mathrm{R}^{2}=0.96$ \\
\hline $\begin{array}{l}\text { Regression } \\
\text { analysis }\end{array}$ & $y=6.221-1.679 \times 10^{-7} x$ & $\begin{array}{l}\text { x: Gross Domestic } \\
\text { Product }\end{array}$ & $\begin{array}{c}\mathrm{R}^{2}=0.99 \\
\mathrm{~F}=408.763\end{array}$ \\
\hline Gray model & $y=85.76 \exp (0.0999 x)-77.76$ & $\mathrm{x}$ : Time sequence & $\mathrm{C}=0$ \\
\hline
\end{tabular}

Table 3: Prediction values of RMB exchanging rates

\begin{tabular}{|c|c|c|c|c|}
\hline & $\begin{array}{c}\text { Time Sequence } \\
\text { curve }\end{array}$ & Regression Analysis & Gray model & $\begin{array}{c}\text { Recommendation } \\
\text { value }\end{array}$ \\
\hline 2015 & 6.1143 & 6.1069 & 5.8779 & 6.087 \\
\hline 2020 & 6.0638 & 6.0624 & 5.3634 & 5.9931 \\
\hline 2025 & 6.0134 & 6.0187 & 5.0508 & 5.9648 \\
\hline
\end{tabular}

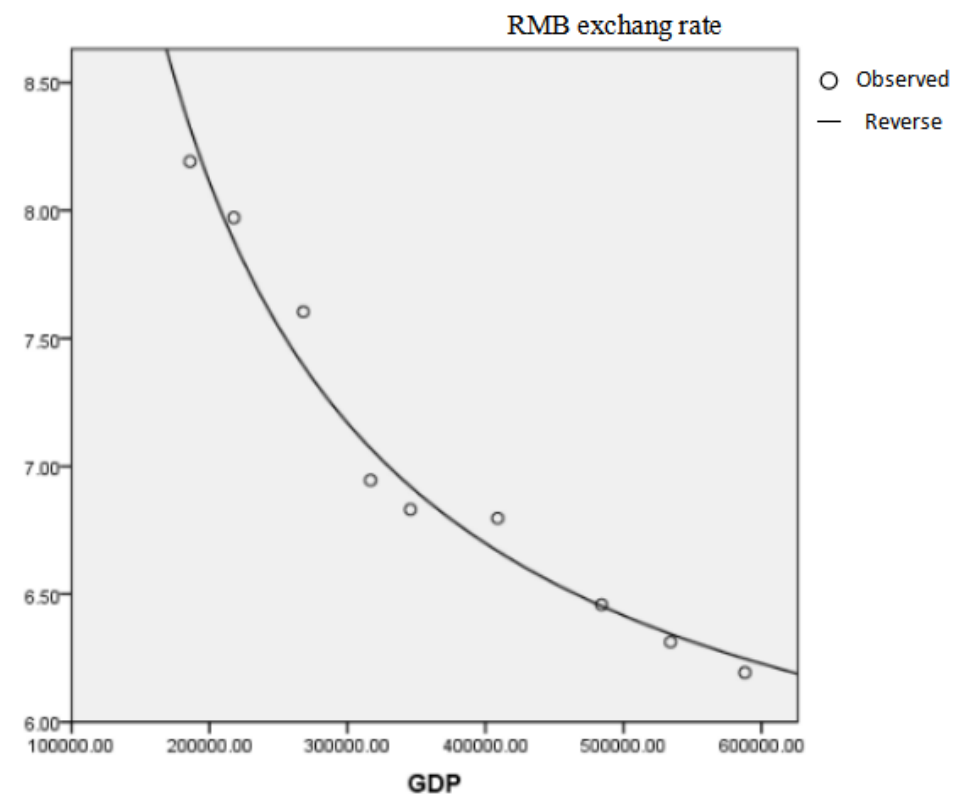

Figure 2: Picture of fitting relationship between RMB exchanging rate and GDP

\section{Countermeasures adopted by financial globalization environment against the national currency sovereignty of China}

To control the speed of RMB appreciation. Export is one of the "three carriages" for the increasing of Chinese economy, while the financial crisis and the deprecation of US dollars against $\mathrm{RMB}$ had led to the reduction of orders obtained by exporting enterprises and resulted in great influences on the exporting enterprises in our nation. In order to prevent the further deterioration of the exporting trend, we should control the speed of the appreciation of RMB against US dollars. This is also a necessary measure for prevent the reduction of the foreign exchange reserve of China. Reasonable levels of exchange rates are helpful for promotion of the export from China and reduce the loss of foreign exchange reserves. It is natural that the slowing down or stopping of appreciation of RMB is possible to reduce the prediction of foreign assets on RMB appreciation and affect the 
inflow of foreign assets, but what has been mainly affected is short-term capital. Viewed from the current trend and status, this is of no harm to the healthy development of Chinese economy because what is mostly needed in China is long-term capital.

Actively promote IMF renovation. A lot of shortcomings had been disclosed in the international financial system by this time of financial crisis, especially that the IMF did nothing in this crisis. EU had proposed to conduct renovation on the IMF, which should be supported by China. The key point is to renovate the operational rules and decision making mechanism of IMF. Viewed from now, the position of China in IMF could not reflect the real strength of China; while the US is enjoying the actual right of veto in this organization, etc.. All these unreasonable mechanism must be renovated. China should strive to increase the proportion of the voting rights in IMF and in the meanwhile also terminate the actual one-vote veto enjoyed by the US in IMF.

To maintain the position of US dollars in the international currency system. This time of financial crisis had weakened the position of US dollars to some degree, while its dominating position has not been fundamentally changed. No matter it is Euro or other currency, none of them is sufficient to constitute material threat to the position of US dollars. The US dollar assets had constituted a large proportion within the China foreign exchange reserve, and it is of no doubt that the declining of US dollars means the deterioration of the Balance Sheet of China. Therefore, it is consistent with the interest of China to maintain the position of US dollars within the international currency system currently. However, it should also been noticed that the US dollars have been issued excessively for a long period, while the inundation of global fluidity resulted from excessive issuance is just one of the fundamental reasons for the occurrence of subprime crisis. Therefore, China should accompany EU and other nations and areas to establish the mechanism for limitation on the international issuance of the currency of US dollars so as to prevent the excessive issuance of US dollars.

\section{Conclusion}

Under the background of the continuous integration, co-movement and deepening of international finance, we should not only utilize international treaties and regulations to protect the currency autonomous rights of our respective nations, actively and explicitly manifest the attitude and standing points in national currency sovereignty, and respond to those powers trying to take the issue of RMB exchange rates to interfere with the progress of the Chinese economy renovation, but also stand on the basic national status and the specialty of the market economy of our nation to improve the construction of the currency law system in our nation, especially to correctly guide the current special financial and currency phenomena occurred in our nation with the fast development of scientific technology and finance into the regulation and supervision of the currency laws in our nation so as to guarantee the effectiveness of the macro regulation and controlling by the central bank of China.

\section{References}

[1] C. Xie. Legal and Economic Relationship between International Currency Cooperation and National Currency Sovereignty under the Background of Economy Integration. Theoretical Cycle 2009(09)

[2] J.H. Zhao. International Economy Coordination and National Currency Sovereignty Assignment. Hubei Social Science. 2009(08)

[3] Q. Liu. Non-linear Adjustment of RMB Actual Exchange Rates Based on STAR Models_—With Comments on Purchasing Power Parity (PPP) Testing Method. Macroeconomic Study. 2013(12)

[4] Q.X. Bai, Z.W. Zhang. Researches on the Effect of Changing RMB Exchange Rates on CPI Inflation Transmissio. International Finance Research. 2011(12) 